\title{
Female Sexual Dysfunction in Elfayoum Governorate
}

\author{
Samar El-Tahlawi ${ }^{1}$, Noha Ezzat Mohammad ${ }^{2}$, \\ Asmaa Younis Elsary ${ }^{3}$, Noha Mohamed Yousef ${ }^{2}$, \\ Talal Abdelreheem²
}

\footnotetext{
${ }^{1}$ Dermatology and Venereology Department, Faculty of Medicine, Cairo University, Cairo, Egypt

${ }^{2}$ Dermatology and Venereology Department, Faculty of Medicine, Elfayoum University, Elfayoum, Egypt

${ }^{3}$ Public Health Department, Faculty of Medicine, Fayoum University, Fayoum, Egypt

Email: nohaezzat1978@gmail.com
}

How to cite this paper: El-Tahlawi, S., Mohammad, N.E., Elsary, A.Y., Yousef, N.M. and Abdelreheem, T. (2018) Female Sexual Dysfunction in Elfayoum Governorate. Advances in Sexual Medicine, 8, 1-13. https://doi.org/10.4236/asm.2018.81001

Received: November 26, 2017

Accepted: January 27, 2018

Published: January 30, 2018

Copyright @ 2018 by authors and Scientific Research Publishing Inc. This work is licensed under the Creative Commons Attribution International License (CC BY 4.0).

http://creativecommons.org/licenses/by/4.0/

(c) (i) Open Access

\begin{abstract}
Introduction: female sexual dysfunction (FSD) is a complex and poorly understood condition that affects females of all ages. Female sexual dysfunction has been a cyclic rather than a linear process that emphasizes biologic, psychological, social, hormonal, and environmental factors. Female sexual dysfunction is a high prevalent disorder reaching up to $60 \%$ of females with reported higher levels in postmenopausal. Aim of the work: was to estimate prevalence of FSD and its related factors in Elfayoum city. Subject and Method: This study was a cross sectional descriptive study conducted in Elfayoum city included 508 married females (above 21 years old) during the period from September 2016 to March 2017. Results: The prevalence of FSD among studied group was $61.2 \%$ versus $38.8 \%$ had normal sexual function, desire dysfunction was $42.3 \%$, arousal dysfunction was $39.2 \%$, lubrication dysfunction was $25 \%$, orgasm dysfunction was $58.5 \%$, satisfaction dysfunction was $58.1 \%$ and pain was $43.3 \%$. There was statistically significant negative correlation between Female Sexual Function Index (FSFI) score and each of female and husband age, duration of marriage, and number of children. Low mean of FSFI score was found among females with irregular menstrual cycle, using contraceptive, not pregnant, mutilated and females who's their husband had erectile or ejaculation disorders. Conclusion and recommendation: High prevalence of FSD among females in Elfayoum governorate. Many factors are found to affect FSD as FGM, each of female and husband age, duration of marriage, and number of children.
\end{abstract}

\section{Keywords}

Female Sexual Dysfunction, Elfayoum 


\section{Introduction}

Sexuality represents an important and integral part of every female life [1]. It is a common problem with significant impact on women, their relationships as well as their overall quality of life [2].

Prevalence of FSD ranges from $26.6 \%$ to $63 \%$ worldwide and even higher in post-menopausal women [3].

Female sexual dysfunction is a multifactor-related problem including psychological and socioeconomic factors. Moreover, female sexual function is usually significantly affected by endocrine factors (prolactin, gonadal hormone] [4].

Partner factors (such as partner's sexual problems and partner's health status) are considered a very important issue that should be sought for after exclusion of other factors [5].

Female genital mutilation defined as partial or complete removal of external female genitals. Four types are recognized varying from removal of clitoral foreskin to removal of all external tissues with sewing up of vaginal opening leaving a small opening for urination and menstruation.

Diagnostic and statistical manual of mental disorders (DSM-5) classification of female sexual dysfunction [6].

- Female orgasmic disorder (FOD).

- Female sexual interest/arousal disorder.

- Genito pelvic pain/penetration disorder.

- Substance/medication-induced sexual dysfunction (in women).

- Other specified sexual dysfunction.

- Unspecified sexual dysfunction.

Many methods estimating FSD in clinical and research settings were established, including questionnaires, structured interviews, and detailed case histories. Questionnaires have been considered an easy first choice to screen individuals and putting them in different classes of FSD [7].

\section{Patients and Method}

Study design: This study was a cross sectional descriptive study conducted on women living in Elfayoum city during the period of 6 months from September 2016 to March 2017 to evaluate the FSD and related risk factor.

Study population: married females (above 15 years old) in Elfayoum city.

Sampling: clustered random sample (represented by married females in reproductive age) from health care facilities (outpatient clinic of Dermatology, STDs and Andrology department-Faculty of Medicine Elfayoum University and 2 Primary health care centers PHC in Elfayoum city).

Sample size: Study included 508 women (had the inclusion criteria).

\section{Exclusion criteria:}

1) Females with any gynecological disorder causing FSD.

2) Females with psychosis or on antipsychotic drugs.

3) Females with neurological disorder. 


\section{Data collection:}

Data were collected by personal interview with self- structured Arabic questionnaire which completed and filled for illiterate females through clarification and explanation provided by researcher.

Female sexual dysfunction was assessed by a detailed 19-item Female Sexual Function Index (FSFI) [8].

Written and Informed consent was obtained from all females. FSFI pro forma was given to females according to their preferred language. Pro forma was pilot tested for cultural appropriateness and linguistic accuracy. Illiterate women were interviewed in person. All six domains of sexual dysfunction, i.e., desire, arousal, lubrication, orgasm, satisfaction, and pain were studied, as shown in Table 1.

Table 1 FSFI total score of $\leq 23.55$ to be diagnostic of FSD [9].

The optimal CVFSFI cutoff score for the FSFI total score was 23.45

$\leq 2.7$ low desire

$\leq 3.15$ arousal

$\leq 4.05$ lubrication disorder

$\leq 3.8$ orgasm disorder

$\leq 3.8$ sexual pain

The optimal CVFSFI cutoff score for the FSFI total score was 23.45 (sensitivity $=66.9 \%$; specificity $=72.7 \%$; area under curve $[\mathrm{AUC}]=0.75$ ). The cutoff score for each domain was also established as follows: $\leq 2.7$ low desire (sensitivity $=$ $55.2 \%$; specificity $=78.3 \%$; $\mathrm{AUC}=0.73$ ); $\leq 3.15$ arousal disorder (sensitivity $=$ 62.1\%; specificity $=76.9 \%$; AUC $=0.74$ ); $\leq 4.05$ lubrication disorder (sensitivity $=86.4 \%$; specificity $=69.8 \%$; AUC $=0.85$ ); $\leq 3.8$ orgasm disorder (sensitivity $=$ $83.3 \%$; specificity $=74.2 \%$; $\mathrm{AUC}=0.85$ ); and $\leq 3.8$ sexual pain (sensitivity $=$ $65.4 \%$; specificity $=80.6 \%$; $A U C=0.79$ ). Using these cutoff scores, we determined the prevalence for FSD, low desire, arousal disorder, lubrication disorder, orgasm disorder, and sexual pain to be $37.6 \%, 23.6 \%, 25.4 \%, 36.8 \%, 30.6 \%$, and $21.8 \%$ in urban Chinese women [9].

\section{Examination:}

General examination was conducted as part of evaluation process with em-

Table 1. Domain Scoring of Female Sexual Function Index.

\begin{tabular}{|c|c|c|c|c|c|}
\hline Domain & $\begin{array}{c}\text { Item } \\
\text { Number }\end{array}$ & Score Range & Factor & $\begin{array}{c}\text { Minimum } \\
\text { Score }\end{array}$ & $\begin{array}{c}\text { Maximum } \\
\text { Score }\end{array}$ \\
\hline Desire & 1,2 & $1-5$ & 0.6 & 1.2 & 6 \\
\hline Arousal & $3,4,5,6$ & $0-5$ & 0.3 & 0 & 6 \\
\hline Lubrication & $7,8,9,10$ & $0-5$ & 0.3 & 0 & 6 \\
\hline Orgasm & $11,12,13$ & $0-5$ & 0.4 & 0 & 6 \\
\hline Satisfaction & $14,15,16$ & $0($ or 1$)-5^{*}$ & 0.4 & 0 & 6 \\
\hline Pain & $17,18,19$ & $0-5$ & 0.4 & 0 & 6 \\
\hline Full Scale Score Range & & & & 1.2 & 36 \\
\hline
\end{tabular}


phasis on signs of diabetes mellitus, hypertension, hyperthyroidism, hypothyroidism, liver disorder.

Local examination of external genitalia was conducted to detect degree of circumcision and to exclude any gynecological disorder.

\section{Ethical consideration:}

In order, to obtain informed by a verbal consent from the participant, first full explanation to women that the study is about women sexual health, they were informed about the aim of the study and they had the right not to participate or end their participation at any stage of the interview and we also take a permission from the doctor responsible for the PHC, all participants were assured of confidentially.

This study was approved from Ethical committee of faculty of medicine, Elfayoum University.

\section{Statistical Analysis}

- Data were collected and coded to facilitate data manipulation and double entered into Microsoft Access and data analysis was performed using SPSS software version 18 in windows 7.

- Simple descriptive analysis in the form of numbers and percentages for qualitative data, and arithmetic means as central tendency measurement, standard deviations as measure of dispersion for quantitative parametric data, and inferential statistic test:

\section{- For quantitative parametric data:}

- In-depended student T-test used to compare measures of two independent groups of quantitative data.

- One way ANOVA test in comparing more than two independent groups of quantitative data with bonferroni Post-HOC to test significance between each two groups.

\section{- For qualitative data}

- Chi square test to compare two of more than two qualitative groups.

- Bivariate person correlation test to test association between variables.

- The P-value 0.05 was considered the cut-off value for significance.

\section{Results}

This study included (508) females from the attendants of the health care facilities (outpatient clinic of Dermatology, STDs and Andrology of faculty of medicine, Elfayoum University, Primary health care and Maternity and child health in EL Fayoum city) during the period from September 2016 to march 2017. The results can be shown in Tables 2-10.

The prevalence of FSD among study group was $61.2 \%$ versus $38.8 \%$ had normal sexual function, desire dysfunction was $42.3 \%$, arousal dysfunction was $39.2 \%$, lubrication dysfunction was $25 \%$, orgasm dysfunction was $58.5 \%$, satisfaction dysfunction was $58.1 \%$ and pain dysfunction was $43.3 \%$, as shown in $\mathrm{Ta}$ ble 6 . 
Table 2. Description of age, age of marriage, duration of marriage and number of children among study group.

\begin{tabular}{ccccc}
\hline Variables $(\mathrm{n}=508)$ & Minimum & Maximum & Mean & SD \\
\hline Female age (years) & 15 & 56 & 28.9 & 7.8 \\
Husband age (years) & 16 & 65 & 34.4 & 8.7 \\
Age of marriage & 13 & 37 & 19.5 & 3.6 \\
Number of children & 0 & 7 & 2 & 1 \\
Duration of marriage & 1 & 40 & 9.3 & 7.2 \\
\hline
\end{tabular}

Table 3. Comparison of working and educational level among study group.

\begin{tabular}{cccccc}
\hline \multirow{2}{*}{ Variables $(\mathrm{n}=508)$} & \multicolumn{2}{c}{ Female } & \multicolumn{2}{c}{ Husbands } & \multirow{2}{*}{ p-value } \\
\cline { 2 - 4 } & Number & $\%$ & Number & $\%$ & \\
\hline Working & & & & & \\
Working & 97 & $19.1 \%$ & 433 & $\mathbf{8 5 . 2} \%$ & \\
Not working & $\mathbf{4 1 1}$ & $\mathbf{8 0 . 9 \%}$ & $\mathbf{7 5}$ & $\mathbf{1 4 . 8 \%}$ & $<0.00 \mathbf{1}^{*}$ \\
Illiterate & 138 & $27.2 \%$ & 160 & $31.5 \%$ & \\
Primary & 16 & $3.1 \%$ & 11 & $2.2 \%$ & \\
Preparatory & 62 & $12.2 \%$ & 36 & $7.1 \%$ & $\mathbf{0 . 0 4}$ \\
Secondary & 195 & $38.4 \%$ & 196 & $38.6 \%$ & \\
University & 97 & $19.1 \%$ & 105 & $20.7 \%$ & \\
\hline
\end{tabular}

Table 4. Description of gynecological history, genital mutilation and its degree among study group, frequency of smoking and sexual problems among husbands of study group.

\begin{tabular}{|c|c|c|}
\hline Variables & Number $(n=508)$ & $\%$ \\
\hline \multicolumn{3}{|c|}{ Menstrual cycle } \\
\hline Regular & 273 & $53.7 \%$ \\
\hline Irregular & 235 & $46.3 \%$ \\
\hline \multicolumn{3}{|c|}{ Contraceptive methods } \\
\hline Yes & 282 & $55.5 \%$ \\
\hline No & 226 & $44.5 \%$ \\
\hline \multicolumn{3}{|l|}{ Pregnancy } \\
\hline Yes & 99 & $19.5 \%$ \\
\hline No & 409 & $80.5 \%$ \\
\hline \multicolumn{3}{|l|}{ Mutilation } \\
\hline Yes & 399 & $78.5 \%$ \\
\hline No & 109 & $21.5 \%$ \\
\hline \multicolumn{3}{|c|}{ Degree of mutilation } \\
\hline $1^{\text {st }}$ & 257 & $64.4 \%$ \\
\hline $2^{\text {nd }}$ & 142 & $35.6 \%$ \\
\hline
\end{tabular}


Continued

\begin{tabular}{ccc}
\hline Smoking & 341 & \\
Yes & 167 & $67.1 \%$ \\
No & & $32.9 \%$ \\
Residence & 291 & \\
Rural & 217 & $57.3 \%$ \\
Urban & & $42.7 \%$ \\
Erection problems & 30 & \\
Yes & 478 & $5.9 \%$ \\
No & & $94.1 \%$ \\
Ejaculation problems & 160 & $31.5 \%$ \\
Yes & 348 & $68.5 \%$ \\
No & & \\
Sexual Satisfaction & 236 & $46.5 \%$ \\
Yes & 272 & $53.5 \%$ \\
No & & \\
\hline & & \\
\hline
\end{tabular}

Table 5. Description of FSFI scores domains and its total score.

\begin{tabular}{ccccc}
\hline Variables $(\mathrm{n}=508)$ & Minimum & Maximum & Mean & SD \\
\hline Desire & 1.2 & 6 & 2.9 & 1.1 \\
Arousal & 1.2 & 5.7 & 3.4 & 1 \\
Lubrication & 1.8 & 6 & 4.4 & 0.76 \\
Orgasm & 1.2 & 6 & 3.2 & 1.3 \\
Satisfaction & 1.2 & 6 & 3.5 & 1.8 \\
Pain & 2.4 & 6 & 3.9 & 0.83 \\
Total FSFI score & 10 & 33 & 21.4 & 5.4 \\
\hline
\end{tabular}

Table 6. Prevalence of FSD among study group.

\begin{tabular}{ccc}
\hline Variables & Number $(\mathrm{n}=508)$ & $\%$ \\
\hline Desire dysfunction & 215 & $42.3 \%$ \\
Arousal dysfunction & 199 & $39.2 \%$ \\
Lubrication dysfunction & 127 & $25 \%$ \\
Orgasm dysfunction & 297 & $58.5 \%$ \\
Satisfaction dysfunction & 295 & $58.1 \%$ \\
Pain dysfunction & 220 & $43.3 \%$ \\
Total FSFI score & 311 & $61.2 \%$ \\
\hline
\end{tabular}

There was statistically significant negative correlation between FSFI score and each of female, and husband age, duration of marriage, and number of children. 
While, there is statistically significant positive correlation between FSFI score and age of marriage, as shown in Table 7.

There was statistically significant difference between different residences in FSFI score with high mean females in habitat urban area, also there was statistically significant difference between different education level, working status of females and their husbands in FSFI score with high mean of FSFI score among highly educated couples and working couples. Regarding smoking FSFI showed no statistical difference, as shown in Table 8.

There was statistically significant difference between different gynecological history of females in FSFI score with high mean of FSFI score among females with regular menstrual cycle, not using contraceptives, pregnant, and non-mutilated. Mutilated females with first degree have higher FSFI score than those with second degree, as shown in Table 9.

Table 7. Correlation between total FSFI score with age and marital variables among study group.

\begin{tabular}{cccl}
\hline Variables & \multicolumn{3}{c}{ Total FSFI score } \\
\cline { 2 - 4 } & $\mathbf{R}$ & p-value & Sig. \\
\hline Female age (years) & -0.14 & 0.002 & HS \\
Husband age (years) & -0.18 & $<0.001$ & HS \\
Age of marriage & 0.18 & $<0.001$ & HS \\
Duration of marriage & -0.24 & $<0.001$ & HS \\
Number of children & -0.22 & $<0.001$ & HS \\
\hline
\end{tabular}

Table 8. Comparisons of total FSFI score in different residence, smoking, educational level and working.

\begin{tabular}{ccccc}
\hline \multirow{2}{*}{ Variables } & \multicolumn{2}{c}{ FSFI score } & \multirow{2}{*}{ p-value } & Sig. \\
\cline { 2 - 3 } Residence & Mean & SD & & \\
Rural & 20.4 & 5.4 & $<0.001$ & HS \\
Urban & 22.8 & 4.9 & & \\
Smoking & & & & \\
Yes & 21.1 & 5.4 & 0.09 & NS \\
$\quad$ No & 21.9 & 5.3 & & \\
Female Working & & & & HS \\
$\quad$ Working & 24.8 & 4.5 & $<0.001$ & \\
$\quad$ Not working & 20.6 & 5.2 & & S \\
Husband Working & & & 0.03 & \\
$\quad$ Working & 21.7 & 5.4 & & \\
Not working & 20.2 & 5.1 & & \\
Husband education level & & & & \\
$\quad$ Illiterate & 19.7 & 5.3 & $<0.001$ & HS \\
\hline
\end{tabular}




\section{Continued}

\begin{tabular}{ccccc}
\hline Female education level & & & & \\
Illiterate & 18.7 & 4.8 & \\
Primary & 18.4 & 5.3 & & \\
Preparatory & 21.8 & 5.1 & $<0.001$ & HS \\
Secondary & 21.7 & 5.2 & & \\
University & 24.9 & 4.3 & \\
Husband education level & & & \\
Illiterate & 19.7 & 5.3 & \\
Primary & 20.1 & 3.4 & & \\
Preparatory & 20.9 & 4.6 & $<0.001$ & \\
Secondary & 21.1 & 5.2 & & \\
University & 24.9 & 4.6 & & \\
\hline
\end{tabular}

Table 9. Comparisons of total FSFI score with gynecological variables.

\begin{tabular}{|c|c|c|c|c|}
\hline Menstrual cy & & & & \multirow[b]{2}{*}{ HS } \\
\hline $\begin{array}{l}\text { Regular } \\
\text { Irregular }\end{array}$ & $\begin{array}{l}22.5 \\
20.1\end{array}$ & $\begin{array}{l}5.1 \\
5.4\end{array}$ & $<0.001$ & \\
\hline \multicolumn{5}{|c|}{ Contraceptive methods } \\
\hline Yes & $\begin{array}{c}20.9 \\
22\end{array}$ & $\begin{array}{l}5.4 \\
5.3\end{array}$ & 0.01 & $S$ \\
\hline \multicolumn{5}{|l|}{ Pregnancy } \\
\hline Yes & 21.1 & $\begin{array}{l}5.4 \\
5.3\end{array}$ & 0.03 & $S$ \\
\hline \multicolumn{5}{|c|}{ Mutilation } \\
\hline Yes & $\begin{array}{l}20.3 \\
25.3\end{array}$ & 3.9 & $<0.001$ & HS \\
\hline \multicolumn{5}{|c|}{ Degree of mutilation } \\
\hline $2^{\text {nd }}$ & 22.6 & 4.5 & $<0.001$ & HS \\
\hline
\end{tabular}

There was statistically significant difference between different husbands sexual problems in FSFI score of their wives, with high mean of FSFI score among females whose husbands had no erectile, or ejaculation problems and feel sexual satisfaction, as shown in Table 10 and Figure 1.

\section{Discussion}

Female sexual dysfunction is a worldwide common problem, its prevalence ranges from $26.6 \%$ to $63 \%$ worldwide [4].

This disorder affects sexual response cycle causing stresses and relationship 
Table 10. Comparisons of total FSFI score in husband sexual problems.

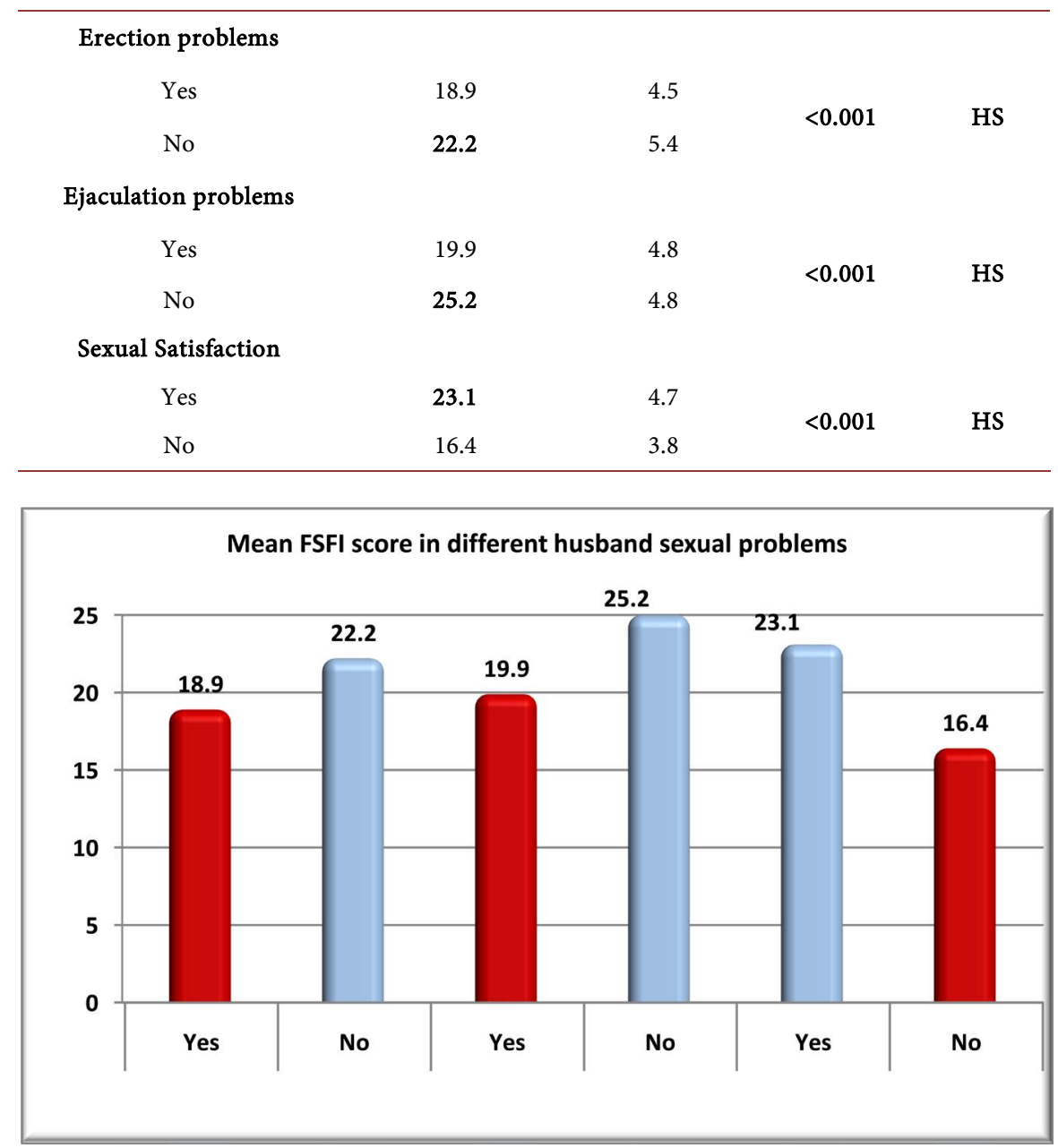

Figure 1. The mean FSFI score in different husband sexual problems.

problems including decrease in sexual desire, sexual arousal disorder, and orgasmic disorder [10].

Female sexual dysfunction is a combination of biological, psychological, social and cultural factors, which makes a total or partial loss of the sexual response [11].

There are many factors contribute to the sexual response, including age, marriage duration, relationship quality, individual psychological problems that roots on childhood relations with parents, and how to cope with emotions [12].

Many methods such as questionnaires, structured interviews, and detailed case histories are used to survey and classification of subjects according to affected sexual domain [7].

The aim of this study was to asses FSD prevalence and associated risk factors among Elfayoum city females. Our study included (508) females from the attendants of the health care facilities (outpatient clinic of Dermatology, STDs and Andrology of faculty of medicine Elfayoum University, Primary health care and Maternity and child health in Elfayoum city) during the period from September 
2016 to march 2017. Females were questioned about FSD by using FSFI and associated factors [8].

In this study the prevalence of FSD among study group was $61.2 \%$. Desire dysfunction was $42.3 \%$, arousal dysfunction was $39.2 \%$, lubrication dysfunction was $25 \%$, orgasm dysfunction was $58.5 \%$, satisfaction dysfunction was $58.1 \%$ and pain dysfunction was $43.3 \%$. In a study by Mamdouh et al.: The FSD prevalence was found to be $53.7 \%$ of women. These variations may reflect medical and psychological factors, particularly in the setting of possible socio-economic and cultural differences, the clinical definition used for each dysfunction, methodology used in data collection and the characteristic of samples studied (general population or gynecology clinics) [13].

In this study orgasm and satisfaction dysfunctions were the most frequent domains of FSD (58.5\% and 58.1\% respectively). Varghese et al. in 2012 had reported orgasm being most common and pain least common disorder among different domains. In another study done by Esfehani et al. in 2016, sexual desire was the most frequent domain of FSD 49.2\%. This difference could be due to variations in cut-off points determined for FSD domains [14] [15].

In this thesis, FGM had a bad impact on FSFI score; mutilated females especially with $2^{\text {nd }}$ degree had worse FSFI score. This result was in agreement with the findings by Mahmoud in 2016 as her work revealed a significant association between FGM and reduction of all aspects of sexual act. This could be explained by the fibrosis and rigid scar tissue following FGM which predisposes to narrowing of the vaginal orifice and muscular spasm which makes intercourse painful and difficult. These physical factors will predispose to psychological one, where the painful experience will drive women to lose both sexual desire and satisfaction [16].

In our study FSFI score significant affection was reported in females whose partners having sexual problems. This was in line with Grewal et al. who reported a significant impact of male partner's sexual functioning on female sexual dysfunction and it was the main predictor for female sexual dysfunction after controlling other variables [17].

On the same line, a study by Jiann and his colleagues confirmed that ED is considered as a risk factor for female dysfunction, including impairment in arousal, orgasm, sexual satisfaction and sexual pain, this may lead to frustration and tension within the relationship, and impact upon her sexual functioning. The impact of ED on a woman sexual function is significant and warrants further attention [18].

In this study, females in urban area had significant higher FSFI score than females in rural area. Also, there is a negative correlation between FSFI score and female age. This result was in agreement with Kunkeri et al. as they found that; desire and orgasm problem were more among women with age $>35$ years, lower education level and those belonging to rural background. Various reasons for this significant finding could be lack of sexual knowledge among these women, 
especially those coming from a rural background and who are uneducated [19].

FSFI score was found to be negatively correlated with duration of marriage and number of children. This result was in agreement with Tehrani et al. in 2014 who had determined that a long marriage life negatively affected the sexual functions. Advancing age of the woman or the couple's loss of interest for each other, or problems arising between the man and wife, increased economic problems in families with larger numbers of children may affect the sexual life of couples [20].

There was statistically significant difference regarding FSFI score in different education level of females and their husbands with high score among highly educated couples. Tekin et al. in 2014 found that the level of sexual function was found to be higher in women with secondary school education than in women with primary school and lower education and in women with university and higher education. This discrepancy in findings can be explained by the interaction of other factors such as age, working status, and duration of marriage, with the educational level. The positive association between FSFI score and education level in our study can explained as a higher educational level may also be associated with an increase in the women's ability freely to express their dissatisfaction which help the woman to solve this problem [21].

In this study, FSFI score was statistically higher among working couples. Work of the wife and her husband plays a role in increasing their income which certainly has a role on their sexual functions. In addition, working is usually associated with good educational level which permits better interconnection.

This result agrees with studies performed in Turkey by Özerdoğan et al. in 2009 as they found close association between income levels with sexual functions [22]. On the contrary, Özkan et al. in 2009 reported that as the income increased, the sexual desire, lubrication and satisfaction decreased [23].

In this study pregnant females had statistically significant higher FSFI score than non pregnant. This is an inconsistent finding with another study by Kuljarusnont et al. [24]. Low percentage of pregnant females (only 19.5\%) in our study doesn't help us to have an appropriate idea about effect of pregnancy on female sexual function.

In this study, females' not using contraceptives had statistically significant higher mean of FSFI score than those using contraceptive methods. Hormonal contraceptive has a well known role in impairing desire domain that negatively affected other domains. This was in agree with İbrahim et al. in 2013 who reported that women practicing hormonal contraception and using intrauterine device had worse FSFI, whereas FSFI was not affected in women practicing no contraception [25].

On the contrary, a study carried out in Colombia reported that the total FSFI score was low in women practicing natural contraception, whereas it was higher in women using modern contraception methods; however, the difference between these two groups was insignificant [26]. 


\section{Conclusion and Recommendation}

There is a high prevalence of FSD among females in Elfayoum governorate. Many factors are found to affect FSD as FGM, each of female and husband age, duration of marriage, and number of children. Large scale studies are recommended to seek for other factors related to FSD.

\section{References}

[1] Stamatiou, K., Margariti, M., Nousi, E., Mistrioti, D., Lacroix, R. and Saridi, M. (2016) (FSD) in Woman Health Care Worker. Materia Socio Medica, 28, 178-182. https://doi.org/10.5455/msm.2016.28.178-182

[2] McCabe, M.P. (2016) Institute for Health and Ageing, Australian Catholic University, Melbourne, Australia Springer Science Business Media New York 2016 307. In: Lipshultz, L.I., et al., Eds., Management of Sexual Dysfunction in Men and Women, University of Piraeus, Piraeus.

[3] Shifren, J.L., Monz, B.U., Russo, P.A., Segret, A., and Johannes, C.B. (2008) Sexual Problem and Distress in United States Women: Prevalence and Correlates. Obstetrics \& Gynecology, 112, 970-978. https://doi.org/10.1097/AOG.0b013e3181898cdb

[4] Lou, W.-J., Chen, B. and Zhu, L. (2017) Prevalence and Factors Associated with Female Sexual Dysfunction in Beijing, China. Chinese Medical Journal, 130, 1389-1394. https://doi.org/10.4103/0366-6999.207466

[5] Balon, R. and Woodard, T.L. (2016) Diagnosis of Female Sexual Dysfunction, Management of Sexual Dysfunction in Men and Women, Department of Psychiatry and Gynecologic Oncology and Reproductive, 213-222HCPA, 2012. 32, 473-479.

[6] American Psychiatric Association (2013) Diagnostic and Statistical Manual of Mental Disorders. 5th Editon, American Psychiatric Association, Arlington.

[7] Giraldi, A., Rellini, A., Pfaus, J.G., Bitzer, J., Laan, E. and Jannini, E.A., et al. (2011) Questionnaires for Assessment of Female Sexual Dysfunction: A Review and Proposal for a Standardized Screener. The Journal of Sexual Medicine, 8, 2681-2706. https://doi.org/10.1111/j.1743-6109.2011.02395.x

[8] Rosen, R., Brown, C., Heiman, J., Leiblun, S., Meston, C.M., Shabsigh, R., Ferguson, D.D., Jr. Agostino, R. (2000) The Female Sexual Function Index (FSFI): A Multidimentional Self-Report Instrument for the Assessment of Female Sexual Function. Journal of Sex \& Marital Therapy, 26, 191-208. https://doi.org/10.1080/009262300278597

[9] Ma, J., Pan, L., Zhang, A. and Kan, Y. (2014) Prevelance of Female Sexual Dysfunction in Urban on Cutoff Scores of the Chinese Version of the Female Sexual Index. Function, J Sex Med, 9, 909-919.

[10] Pinto, A.C. (2013) Sexuality and Breast Cancer: Prime Time for Young Patients. Journal of Thoracic Disease, 5, S81-86.

[11] Vettorazzi, J., Marques, F., Hentschel, H., Ramos, J.G.L., Martins-Costa, S.H. and Badalotti, M. (2012) Sexuality and the Postpartum Period: A Literature Review.

[12] Anderson, J.L. (2013) Acknowledging Female Sexual Dysfunction in Women with Cancer. Clinical Journal of Oncology Nursing, 17, 233-235. https://doi.org/10.1188/13.CJON.233-235

[13] Mamdouh, H.M., Abdou, A.M., Kharboush, I. and Shama, M. (2017) Prevalence and Characteristics of Female Sexual Dysfunction among a Sample of Egyptian Women. American Journal of Research Communication, 5, 62-74. 
[14] Varghese, K.M., Bansal, R., Kekre, A.N. and Jacob, K.S. (2012) Sexual Dysfunction among Young Married Women in Southern India. International Urogynecology Journal, 23, 1771-1774. https://doi.org/10.1007/s00192-012-1782-3

[15] Esfehani, R.J., Fazel, N., Dashti, S., Moshkani, S., HaghighiHasanabad, F., Foji, S. and Kamalimanesh, B. (2016) Female Sexual Dysfunction and Its Associated Risk Factors: An Epidemiological Study in the North-East of Iran. Journal of Midwifery and Reproductive Health, 4, 498-505.

[16] Mahmoud, M.I.H. (2016) Effect of Female Genital Mutilation on Female Sexual Function, Alexandria, Egypt. Alexandria Journal of Medicine, 52, 55-59. https://doi.org/10.1016/j.ajme.2015.03.003

[17] Grewal, G.S., Gill, J.S., Sidi, H., Gurpreet, K., Jambunathan, S.T., Suffee, N.J., Midin, M., NikJaafar, N.R. and Das, S. (2014) Prevalence and Risk Factors of Female Sexual Dysfunction among Healthcare Personnel in Malaysia. Comprehensive Psychiatry, 55, S17-S22.

[18] Jiann, B.P., Su, C.C. and Tsai, J.Y. (2013) Is Female Sexual Function Related to the Male Partners' Erectile Function? The Journal of Sexual Medicine, 10, 420-429.

[19] Kunkeri, S.P., SathyanarayanaRao, T.S. and Andrade, C. (2017) Study of Sexual Functioning and Disorder in Women before and after Tubal Sterilization (Tubectomy). Indian Journal of Psychiatry, 59, 63-68.

[20] Tehrani, F.R., Farahmand, M., Simbar, M. and Afzali, H.M. (2014) Factors Associated with Sexual Dysfunction; A Population Based Study in Iranian Reproductive Age Women. Archives of Iranian Medicine, 17, 679-684.

[21] Tekin, B.Y., Ural, Ü.M., Üstüner, I., Balık, G. and Güvendağ Güven, E.S. (2014) Evaluation of Female Sexual Function Index and Associated Factors among Married Women in North Eastern Black Sea Region of Turkey. Turkish Journal of Obstetrics and Gynecology, 11, 153-158. https://doi.org/10.4274/tjod.43815

[22] Özerdoğan, N., Sayıner, F.D., Köşgeroğlu, N. and Ünsal, A. (2009) 40-65 Yaş Grubu Kadınlarda Cinsel Fonksiyon Bozukluğu Prevalansı, Depresyon Ve Diğerílişkili Faktörler. Maltepe Üniversitesi Hemşirelik Bilimve Sanatı Dergisi, 2, 46-59.

[23] Ozkan, S., Demirhan, H., OzenCinar, İ. and GebelikveBazı (2009) Sosyodemografik Ozelliklerin Cinsel Fonksiyon Uzerine Etkisi. Ataturk Universitesi Hemşirelik Yuksekokulu Dergisi, 12, 28-37.

[24] Kuljarusnont, S., Russameecharoen, K. and Thitadilok, W. (2011) Prevalence of Sexual Dysfunction in Thai Pregnant Women. Thai Journal of Obstetrics and Gynaecology, 19, 172-180.

[25] Ibrahim, Z.M., Ahmed, M.R. and Ahmed, W.A. (2013) Prevalence and Risk Factors for Female Sexual Dysfunction among Egyptian Women. Archives of Gynecology and Obstetrics, 287, 1173-1180. https://doi.org/10.1007/s00404-012-2677-8

[26] Echeverry, M.C., Arango, A., Castro, B. and Raigosa, G. (2010) Study of the Prevalence of Female Sexual Dysfunction in Sexually Active Women 18 to 40 Years of Age in Medellín, Colombia. The Journal of Sexual Medicine, 7, 2663-2669.

https://doi.org/10.1111/j.1743-6109.2009.01695.x 